\title{
AUDITORIA DE PESSOAL
} SIEGFRIED HOYLER

\begin{abstract}
"Ao analisar cada problema, o administrador do pessoal deve certificar-se de que suas sugastões de solução se coadunem com as exigências das diretrizes da emprêsa." - PAUl PIgors e Charies A. MYERS.
\end{abstract}

O têrmo "auditoria" evidencia sua origem latina do vocábulo auvitor. A rigor, poderíamos afirmar que auditoria é o processo de "ouvir" ou "auscultar" o funcionamento de uma emprêsa, com a finalidade de avaliar a execução de práticas e políticas da emprêsa e analisar quão bem estas se ajustem à consecução dos objetivos propostos pela sua mais alta administração.

O uso mais comum do têrmo está relacionado com a Contabilidade; não apenas com o manuseio de dinheiro, mas igualmente com o contrôle de recebimento dos materiais, fôlhas de pagamento, inventários, práticas e concorrências do departamento de compras etc.. À auditoria compete verificar, por exemplo, se as pessoas indicadas estão efetivamente trabalhando como e onde a fôlha de pagamento indique, bem como se os descontos sôbre materiais comprados são efetivos ou não. Enfim, o auditor contábil analisa tôdas as práticas e atos relacionados com materiais, mão-de-obra ou qualquer outro fator de produção que envolva custos.

Siegraied Hoyler - Getente de Relações Industriais e Públicas da Aluminio do Brasil S. A.. 
Como a economia ocidental, em função de inúmeros fatòres que não nos cabe identificar aqui, vem marchando històricamente da posição de "capitalismo individualista" para a de "capitalismo social", é natural que a primeira preocupação da auditoria, porque correspondente com a principal ou mesmo única preocupação das emprêsas no passado, haja sido de ordem puramente contábil e, conseqüentemente, econômico-financeira.

Assim, a auditoria contábil já pode ser considerada como prática normal na maioria das médias e grandes emprêsas . Analisando-se, porém, essas mesmas emprêsas com um serviço de auditoria contábil já estabelecido, notamos que essa auditoria contábil, em função da mesma preocupação básica dos custos ou, pelo menos, da realização dos seus objetivos, não esgota todo o campo de preocupações fundamentais da emprêsa. Por exemplo, uma estrutura orgânica deficiente, ultrapassada ou viciada pode ser ainda mais perigosa aos interêsses máximos da emprêsa do que o são os falsos critérios de venda de refugos ou de sucata, examinados pela auditoria contábil.

Por isso foi que muitas emprêsas passaram a implantar programas de auditoria de relações industriais ou auditoria de pessoal ou ainda - quando indiscriminadamente denominados - inventário de pessoal, pesquisa de pessoal, auditoria industrial etc..

DALE YODER assim se refere à auditoria de pessoal: "A auditoria de pessoal promove uma oportunidade para revisão, crítica e avaliação do trabalho de pessoal e de todo o programa da gerência (ou supervisão) de mão-de-obra. Ela analisa os relatórios; coleta, organiza e interpreta os dados relatados. À luz de tais dałlos e interpretações, ela avalia as decisões tomadas por tôda a gerência". ${ }^{1}$

ScotT assim a define: "Auditoria de pessoal é uma análise de todos os fatôres envolvidos na administração de

1) D. Yoder, Personnel Management and Industrial Relations, Nova Iorque: Prentice-Hall, Inc., 1945. 
pessoal, com um sumário da situação encontrada, seguida de recomendações destinéslas a corrigir qualquer desvio dos padrões determinados". 2

YODER volta a insistir em que "uma auditoria de relações industriais não pode ficar confinada à apreciação do que a assessoria de pessoal ou de relações industriais vem realizando. Deve considerar também a influência e a eficácia dêsses programas nas atitudes de todos aquêles que tenham responsabilidades de liderança, o que inclui todos os níveis de supervisão e gerência da emprêsa. A auditoria examina as ações dos executivos e diretores particularmente no desenvolvimento e aceitação de políticas sadias de administração de pessoal. A auditoria avalia as atividades dos gerentes de "linha" e supervisores na execução das políticas estabelecidas. Igualmente, analisa a assessoria de pessoal, avaliando o desempenho das suas funções técnicas ou profissionais". ${ }^{3}$

Criam-se algumas vêzes confusões entre auditoria de pessoal e programas de avaliação de desempenho, pesquisa do moral etc.. Realmente, o programa de avaliação dos empregados, as pesquisas do moral etc. constituem parte da preocupação da auditoria de pessoal, distinguindo-se dela, portanto, como a parte se distingue do todo. "A auditoria" - afirma YODER — "avalia politicas, programas e práticas de pessoal, bem como reações dos empregados expressas, por exemplo, nas pesquisas do moral"."

$O$ auditor de pessoal pode começar seu trabalho com a indagação de quais sejam os objetivos propostos à administração humana. Considerará, por exemplo, as políticas relativas a salários, a limite de idade para admissão ou a desenvolvimento de executivos. Ao mesmo tempo, ana-

2) Walter Dill Scott e outros, Personnel Menagement, Nova Icrque: McGraw-Hill Rock Co., Inc., 6. ${ }^{\text {a }}$ edição, 1961.

3) D. YODER, op. cit..

4) Idem, ibidem. 
R.A.E. $/ 17$

lisará os programas destinados a desenvolver tais políticas: avaliação de cargos, programas de seleção, programas de treinamento etc.. Particularizando ainda mais, passará a analisar as rotinas da companhia, cuidando de verificar se são ou não adequadas ao fim a que se destinam, ou seja, orientar a execução dos programas adotados. Finalmente, restará verificar quando e até que ponto estarão sendo essas rotinas comunicadas aos interessados $\theta$ por êstes aceitas, determinando-se os resultados de sua observância.

PRINCÍPIOS DE AUDíTORIA DE PESSOAL

A Auditoria de Pessoal é campo demasiado amplo para ser confinado a poucas normas ou regras rígidas. E preciso, porém, alertar o auditor com relação a uns tantos princípios gerais que devem ser levados em conta para que seu trabalho seja frutífero. Enunciá-los-emos a seguir.

- É preciso conhecer, em primeiro lugar, o objetivo que se tem em vista. A curiosidade dos números, o prazer da pesquisa, o diletantismo e o perfeccionismo poderão absorver de tal forma o auditor ou distraí-lo em tal medida que poderão vir a prejudicar sèriamente o seu trabalho. Faz-se mister, pois, evitar êsse risco mediante clara especificação do objetivo proposto à auditoria, determinando-se a extensão e a profundidade desejáveis na consecução dêsse objetivo, a orientação a ser seguida e as conclusões esperadas.

Em seguida, é necessário efetuar a auditoria de relações industriais, a partir dos objetivos do pessoal da emprêsa. Eis o que declara ScotT a êsse respeito: "Poucos homens de negócios têm definido com clareza os objetivos de Pessoal. [ ...] Administração de pessoal é a atividade da emprêsa que se empenha em aproveitar os recursos humanos em uma organização efetiva, providenciando oportunidades para o máximo de contribuição individual, sob condições de trabalho favoráveis, promoven- 
do o desenvolvimento individual e estimulando confiança e compreensão recíprocas entre empregador e empregados, bem como entre os próprios empregados".

Apesar de pouco claros para muitos os objetivos de pessoal da emprêsa, é dentro dêles que se deve conduzir a auditoria de relações industriais, uma vez que determinam o clima das inter-relações humanas, fora do qual muitas generosas tentativas do oferecer subsídios para ajustes ou correções estariam fadadas ao fracasso.

Embora constitua significativo estímulo para criar no trabalho um clima que encoraje a equipe a agir com honestidade, a auditoria de pessoal não pode ser conduzida na suposição de que a equipe seja desonesta. Muitas vêzes, numa simples questão de pagamento de empregados: com sistema de incentivos por produção, por exemplo, o supervisor poderá parecer próximo à desonestidade, se não tiver um contrôle assíduo sôbre a produção do seu pessoal. Outras vêzes, empregados antigos e de confiança reúnem as funções de pagador e departamento do pessoal, por exemplo, sem nenhum contrôle suplementar. Tais erros, em princípio, devem ser atribuídos a vícios fundamentais da própria estruturação da emprêsa; só depois de esgotadas essas possibilidades será viável levantar suspeitas quanto à moralidade de alguém.

- É psicològicamente infeliz iniciar uma avaliação de qualquer situação empresária com atitude mental negativa, isto é, com a suposição gratuita de que as rotinas existentes devam estar erradas. Nem tôda a inovação significa melhora. $O$ trabalho de auditoria, como depende de consultas e buscas, não pode prescindir da colaboração de vários setores. $\mathrm{E}$ é natural que difìcilmente se possa contar com essa colaboração quando se parte do pressuposto de que tudo quanto exista esteja errado e precise ser modificado.

5) W. D. ScoTT, op. cit.. 
- Constitui tendência humana perigosa admitir pacìficamente que as práticas correntes devam ser corretas pelo simples fato de estarem em uso há muito tempo. A atitude simplista de muitos administradores ao suporem que determinada prática deva ser a melhor só porque esteja consagrada por uso prolongado ou aceitação generalizada contagia, por vêzes, os próprios auditores, impedindó-lhes a análise objetiva dos fatos.

- Tenha-se presente que a natureza humana não raro induz o homem a resistir a inovações. Também é possí-; vel encontrar a aceitação entusiástica de inovações pelo simples fato de serem inovações. Ambas tendências representam para o auditor óbices à procura da verdade ou do melhor método.

O TRABALHO DO AUDITOR

A primeira tarefa pròpriamente dita do auditor é a de obter os fatos talqualmente ocorrem. Para facilitar a obtenção dêsses fatos o auditor poderá formular, com referência a cada função de relações industriais, questões como estas: ${ }^{6}$

- Porque foi implantada essa prática, êsse programa ou essa política? Ela ainda se justifica? Qual seria o resultado se ela fôsse abolida?

Tal necessidade é parcialmente satisfeita por outro método?

- É essa a melhor prática, à luz das atuais circunstâncias?

- Que mudanças poderiam aumentar a eficiência dessa prática?

Deveriam essas alterações ser introduzidas de uma vez ou gradativamente?

6) Idem, ibidem. 
Essa modificação é parte de outra modificação sugerida, ou deve ser mantida como sugestão independente?

- Qual é o tempo necessário e apropriado para efetivar a alteração?

A aproximação científica de uma auditoria pode ser resumida nos seguintes passos fundamentais:

- Considerar os objetivos propostos.

- Obter os fatos.

- Avaliar os fatos presentes à luz dos objetivos propostos.

- Formular um plano de melhoria das práticas atuais a fim de melhor atingir os objetivos propostos (se êstes não puderem ser atingidos adequada e plenamente).

- Estabelecer um cronograma para a implantação das mudanças propostas.

Evidentemente, êsse roteiro não é aplicável sòmente à avaliação da administração de pessoal, mas também à avaliação de qualquer outra atividade administrativa.

PLANO DE AUDITORIA DE PESSOAL

Um plano de auditoria de pessoal e sua aplicabilidade estão condicionados (a) aos objetivos da auditoria, $(b)$ aos objetivos, tipo, localização e tamanho da emprêsa, (c) à extensão das funções de relações industriais, $(d)$ a fatôres materiais de tempo e custo, (e) à capacidade da gerência, $(f)$ à objetividade da equipe, $(g)$ ao moral do grupo e $(h)$ a inúmeros outros fatôres.

Esperando poder auxiliar aquêles que se propõem a realizar uma auditoria de pessoal ocasional e jamais nos propondo cobrir a ampla gama de questões cuja extensão e possibilidade de ocorrência está limitada sòmente pela imaginação do auditor, formulamos adiante 160 questões que se não esgotam todo o variado e amplo campo das relações industriais, permitem dar ao auditor, ou ao geren- 
te de relações industriais, ou à alta direção da emprêsa um acervo de questões que cobrem, dentre as muitas áreas de pessoal (planos assistenciais, relações trabalhistas, comunicações, higiene, segurança etc.) cinco áreas escolhidas, a saber:

- organização

- recrutamento e seleção

- treinamento

- avaliação de desempenho

- administração de salários.

Scotr assim se refere ao uso das listas de questões: "Algumas pessoas se opõem ao uso de listas de questões. Porém, quando inteligentemente usadas como guias, essas listas podem ser úteis para evitar lacunas sôbre dificuldades que devam ser sanadas. Se fôr uma auditoria completa, naturalmente a lista de contrôle abrangerá cada fase da função de pessoal. Se a auditoria focalizar apenas algum aspecto especial da função de pessoal, a lista de questões fará referência exclusivamente ao aspecto que esteja sob auditoria. A lista de questões para uma loja de departamentos incluiria certas perguntas específicas: peculiares aos problemas de um estabelecimento de vendas ao consumidor. No item "Recrutamento e Seleção", por exemplo, incluiria a seguinte questão: " $E$ mantida uma lista de ex-vendedores que possam trabalhar durante períodos de maior movimento?".

Em qualquer hipótese, uma lista de questões será útil à emprêsa, ao menos como um bom início para a prática salutar de avaliar periòdicamente a administração do potencial humano, oferecendo à direção um quadro mais ou menos seguro do nível, da eficiência e dos problemas da administração de pessoal, especialmente nas grandes emprêsas.

7) Idem, ibidem. 


\section{A. Organização}

\section{Geral}

1.1 Existe um organograma da emprêsa como um todo?

1.2 O organograma é seguido? Ou a estrutura informal tem interferência nêle?

1.3 O organograma é atualizado? Com que frequiência?

1.4 Quem é o responsável pela coordenação da organização?

1.5 O organograma é comunicado eficientemente? Como?

1.6 Condiz o organograma com os objetivos $\mathrm{e}$ com as políticas da emprêsa?

1.7 Há definição precisa da quantidade e da qualidade de autoridade delegada a cada membro da equipe?

1.8 Há cooperação recíproca, respeito e reconhecimento entre os setores de assessoria e os de "linha"?

1.9 O setor de relações industriais é solicitado a participar do planejamento da organização?

1.10 Quantos subordinados respondem a cada chefe? É adequado êsse número?

1.11 Existe relação de subordinação entre órgãos controlados e controladores, por exemplo, compras e almoxarifado, contabilidade e caixa, produção e contrôle de qualidade?

1.12 Existe relação de subordinação entre órgãos de interêsses antagônicos, como por exemplo 
produção e manutenção, vendas e crédito, vendas e cobrança etc.?

1.13 Existe um manual de organização com a descrição geral dos cargos?

1.14 Quem é o responsável pela atualização do manual de organização?

1.15 Há políticas e rotinas de trabalho (normas de procedimento) definidas?

2. Departamento do Pessoal

2.1 O departamento do pessoal tem suas práticas de pessoal bem definidas? Essas práticas são seguidas e asseguram um tratamento eqüitativo dos casos tratados?

2. 2 O departamento do pessoal reúne tôdas as funções de pessoal, ou estas estão dispersas pela emprêsa?

2.3 O departamento do pessoal conhece a sua função de assessoria na emprêsa?

2.40 departamento de pessoal possui os recursos materiais e humanos suficientes para o desempenho de sua função?

2.5 Os outros departamentos utilizam-se adequadamente dos recursos do departamento do pessoal? Se não, porque?

2.6 Qual a organização formal do departamento do pessoal?

2.7 Ela adequada?

B. Recrutamento e Seleção

1. Há uma política de recrutamento definida quanto:

1.1 ao trabalho de mulheres? 
1.2 ao trabalho de menores?

1.3 à admissão de parentes?

1.4 à readmissão de ex-empregados?

1.5 à admissão de empregados de emprêsas concorrentes?

1.6 à formação de subgrupos (políticos, raciais, religiosos, étnicos etc.)?

1.7 à idade máxima de admissão?

1.8 às fontes de recrutamento?

2. E justificável essa política ou deve ser reformulada? Porque? Em que têrmos?

3. Qual o processo seguido para solicitar o preenchimento de vagas?

4. Há algum formulário a ser preenchido?

5. Constam dêle todos os requisitos desejáveis no candidato?

6. Quem aprova o formulário?

7. O processo é simples e ao mesmo tempo seguro?

8. Existe aprovação prévia do efetivo de pessoal?

9. Há dias específicos para atendimento de candidatos?

10. Já se fêz alguma análise do rendimento ou eficiência das fontes de recrutamento?

11. Há previsão orçamentária para o recrutamento?

12. Qual a relação entre a despesa estimada e a real?

13. Qual a relação entre a média de despesa mensal com recrutamento do corrente ano e a média dos últimos cinco anos? 
14. Se houver sensível diferença, como justificá-la?

15. Existe uma rotina para a seleção?

16. Qual é essa rotina?

17. Essa rotina é simples, adequada e completa?

18. Trabalha o setor de seleção com profissiografias?

19. O departamento do pessoal mantém-se em sua função de assesoria no que diz respeito à seleção?

20. Realiza-se prova profissional? Por quem?

21. Todos os candidatos indicados pelo setor de seleção são devidamente entrevistados pelo chefe imediato?

22. Procede-se a exame médico? Como? Onde? Quando? Por quem?

23. Efetuam-se testes psicotécnicos? Por quem? Quando?

24. Quais as provas que compõem a bateria de testes?

25. São elas adequadas? Qual a sua validade?

26. Existe contrôle posterior dos resultados das provas psicotécnicas?

27. Como foram obtidos os padrões para as provas psicotécnicas em uso?

28. Faz-se uma entrevista regular com o candidato a emprêgo? O local da entrevista é adequado? Bem iluminado (sem ofuscação)? Razoàvelmente privado?

29. Quem realiza a entrevista? É a pessoa indicada à tarefa?

30. Há um roteiro de entrevistas? E adequado?

31. Qual a relação entre as anotações do entrevistador e a experiência posterior da companhia com o empregado? 
32. Quais as fontes de referências solicitadas dos candidatos? Essas fontes são as adequadas? São consultadas?

33. Qual a consistência entre essas fontes e a experiência com candidatos?

34. Qual o tempo médio mensal para preenchimento das vagas solicitadas nos últimos 12 meses?

C. Treinamento

1. Existe treinamento na emprêsa?

2. Quem é o responsável pela execução do programa de treinamento?

3. O setor de treinamento está adequadamente subordinado ao departamento do pessoal?

4. Quem é o responsável pelo levantamento das necessidades de treinamento da emprêsa?

5. Existe contrôle dos resultados do treinamento? Qual? É adequado?

6. Quem é o responsável pelo contrôle?

7. Existe programa de integração de novos empregados?

8. Quem é o responsável por êle?

9. Com que freqüência são realizadas as palestras de integração?

10. Essas paiestras são ilustrađas e interessantes?

11. Existe a preocupação de não tornar as palestras demasiadamente mecânicas e formais?

12. Utilizam-se cursos externos de treinamento?

13. Há contrôle dos resultados dêsses cursos?

14. Existe algum processo para seleção dos treinandos? Qual? E adequado? 
15. Faz-se algum levantamento sistemático das necessidades de treinamento da emprêsa?

16. Existe orçamento próprio para o treinamento? É adequado?

17. Qual a relação existente entre a previsão de despesas com treinamento e o real despendido?

18. É o setor de treinamento solicitado a colaborar com a "linha" no preparo do pessoal?

19. Existe trabalho coordenado entre a engenharia de métodos e o treinamento?

20. Como é o treinamento apreciado pelos setores de "linha"?

21. Há programa de treinamento no local de trabalho?

22. Aplica-se o Twr?

23. Há programa de treinamento de vendedores?

24. As funções que mais exigem treinamento estão devidamente descritas por manuais de treinamento?

25. Há um programa de desenvolvimento de executivos?

26. Há previsão de substituição adequada para cada executivo atual?

27. Há biblioteca técnica na.emprêsa? Bem instalada? Consultada?

D. Avaliação de Desempenho

1. Há algum plano aprovado de avaliação de desempenho na emprêsa?

2. É adequado, simples e eficiente?

3. Está sendo seguido efetivamente?

4. Com que freqüência e em que ocasiões são feitas as avaliações? Porque? 
5. Como a distribuição geral das avaliações se compara com a curva normal?

6. Para que são utilizados os resultados da avaliação de desempenho? Aumentos salariais? Promoções? Treinamento? Demissões ou dispensas?

7. Ccmo a emprêsa se precavê contra a tendência de superavaliação dos empregados pelos supervisores?

8. Os supervisores são submetidos a treinamento regular no que diz respeito à avaliação de desempenho?

9. Os empregados são regularmente informados quanto aos resultados das avaliações? Por quem? Como?

10. Qual o turnover da companhia no último mês findo?

11. Qual o turnover médio mensal da companhia no ano em curso?

12. Qual o turnover médio mensal da companhia no ano anterior?

13. Qual o turnover médio mensal da companhia nos últimos cinco anos?

14. Quais as razões que explicam as diferenças?

15. É realizada sistemàticamente a entrevista de saída?

16. Quais os motivos de saída dos empregados, dentro do seguinte esquema:

16. 1 por iniciativa do empregado:

16.1.1 saúde?

16.1.2 remuneração insuficiente?

16.1.3 aposentadoria por tempo de serviço?

16.1.4 obrigações de família? 
16.1.5 interêsse por outro tipo de trabalho?

16.1.6 interêsse por outro local de trabalho?

16.1.7 higiene de trabalho?

16.1.8 falta de carreira?

16.1.9 ambiente de trabalho?

16.1.10 insatisfação $\mathrm{ccm}$ o chefe?

16.2 por iniciativa da emprêsa:

16.2.1 redução do efetivo do pessoal?

16.2.2 desempenho insatisfatório:

16.2.2.1 quanto ao rendimento?

16.2.2.2 quanto à conduta?

16.3 por fôtça maior:

16.3.1 morte?

16.3.2 aposentadoria ccmpulsória?

16.4 Outros? Quais?

E. Administração de Salários

1. Possui a emprêsa um prcgrama de avaliação de cargos?

2. E êsse sistema apropriado?

3. Está efetivamente implantado? Estão todos os cargos descritos e avaliados?

4. Qual é o apoio que lhe dá a alta administração da emprêsa?

5. Qual a opinião da supervisão de "linha" sôbre o programa de avaliação de cargos? 
6. Os empregados são entrevistados para a descrição de cargos?

7. As descrições apresentam-se sob um mesmo estilo ou padrão?

3. As descrições de cargos estão razoàvelmente atualizadas?

9. As descrições de cargos são utilizałlas devidamente para a seleção de empregados, para a análise da organização e definição de responsabilidades?

10. O título dos cargos é o mesmo do usado nos registros do pessoal, nos organogramas etc.? A nomenclatura é allequada?

11. Os cargos são codificados? Essa codificação é prática e útil?

12. Como são aprovadas as avaliações?

13. Está assegurado um meio de analisar e corrigir eventuais discrepâncias nas avaliações? Os supervisores participam dessas correções?

14. Há um sistema de salários próprio da companhia?

15. E completo? Prevê:

15.1 aumentos por mérito?

15.2 reajustamentos proporcionais aos aumentos do custo de vida?

15.3 outros aumentos ou reajustamentos?

16. Há alguém ou algum setor diretamente responsável pela efetivação do plano de avaliação de cargos e pela aplicação da política salarial da emprêsa?

17. Tem êsse setor definida sua posição de assessoria na emprêsa, para evitar choques desnecessários ou evidência indesejável? 
18. Há pagamento por incentivos? Porque? Se o há, é justo?

19. Há adiantamentos de salários? Porque?

20. Em caso afirmativo, são necessários?

21. Em caso afirmativo, são devidamente controlados? Porque? Como?

22. Faz-se previsão anual de salários? A previsão é acompanhada?

23. Os salários são confidenciais? Justifica-se essa medida? Porque?

24. A emprêsa participa de pesquisas de salários? Em que categoria de cargos? Como é feita?

25. Tais pesquisas são representativas e atendem à estrutura salarial?

26. Verifica-se periòdicamente a relação entre os salários internos e os do mercado? Efetuam-se ajustes na estrutura de salários, levando-se em consideração os dados do mercado?

27. Existem faixas salariais? A defasagem das faixas é adequada?

28. Os aumentos de salários estão documentados?

29. Como é estabelecido o salário de admissão?

30. Qual a rotina de informação entre o setor de salários e a pagadoria?

31. Na prática, qual a relação entre o custo de vida e os salários da emprêsa nos últimos 24 meses? Porque?

32. Qual a relação entre os salários médios e a produção per capita nos últimos cinco anos?

33. Como se justifica essa relação? 
34. Qual a relação entre a fôlha de pagamento do pessoal burocrático e a do pessoal de operações nos últimos cinco anos?

35. Como se justifica essa relação?

36. Qual a prática de determinação de salários na companhia?

37. O chefe imediato participa adequadamente dessa determinação?

38. A avaliação de mérito é tida em conta para a aprovação de aumentos?

\section{CONCLUSÃO}

Enfim, a auditoria de pessoal tem na área de Pessoal a mesma finalidade geral da auditoria contábil na área de Finanças. Scotr, a respeito, explica: "Da mesma forma que o inventário serve de base para o planejamento do próximo período de produção, a auditoria de pessoal deveria servir de fundamento à planificação das atividades de pessoal para o próximo período".

A auditoria de pessoal pode indicar fatos ou falhas que nunca seriam conhecidos sem ela. Diz Saltonstall: "Poucas pessoas questionarão a conveniência de avaliar a eficiência da administração de pessoal. $O$ fato de que o comportamento humano não é suscetível de ser previsto com exatidão não deveria desacreditar os esforços para alcançar uma avaliação mais precisa no campo de Pessoal. Bàsicamente, deve ser considerado um objetivo valioso ajudar a gerência a reconhecer progressos feitos, identificar problemas existentes e interpretar tendências e medidas efetivas, cujo entendimento possibilite um planejamento inteligente de ações capazes de satisfazer individual e gru-

8) Idem, ibidem. 
palmente os empregados e assim incentivar-lhes a produtividade para o máximo rendimento nos negócios".

É êsse o objetivo geral da auditoria de pessoal.

\author{
BIBLIOGRAFIA
}

Rogert M. Greaghead, "Why and How to Conduct a Management Audit", Washington Government Printing Offics, Chamber of Commerce of the United States, 1948.

Thomas J. Luck, Personnel Audit and Appraisal, Nova Iorque: McGraw-Hill Book Co. Inc., 1955.

Walter Dill ScotT e outros, Personnel Management, Nova Iorque: McGraw-Hill Book Co. Inc., 6. ${ }^{\text {a }}$ ediçãc, 1961.

DALE Yoder, Personnel Management and Industrial Relations, Nova Ícrque: Prentice-Hall Inc., 1945.

Idem, Handbook of Personnel Management and Labor Relations, Nova Iorque: McGraw-Hill Book Co. Inc., 1958.

Robert Saltonstall, "Evaluating Personnel Administration", Harvard Business Revicw, Vol. 30, N. 6, ñvembro/dezembro de 1952.

Robert H. Willy, "Qual Vol. 32, n. ${ }^{\circ} 3$, novembro de 1955.

9) Robert Saltonstall, "Evaluating Personnel Administration", Harvard Business Review, Vol. 30, N. ${ }^{\circ} 6$, novembro/dezembro de 1952. 